\title{
Estaquia de Croton zehntneri Pax et Hoffm. com diferentes concentrações de ácido indol butírico
}

\author{
Cuttings of Croton zehntneri Pax et Hoffm. At different concentrations of indole butyric acid
}

\author{
Cleyton Saialy Medeiros Cunha' ${ }^{\mathrm{I}}$ Sandra Sely Silveira MaiaII Maria de Fatima Barbosa Coelho ${ }^{\mathrm{II}}$
}

\section{RESUMO}

Croton zehntneri Pax et Hoffm. (canela de cunhã) é nativa do nordeste do Brasil, tem efeito antioxidante e atividade antinociceptiva e antidepressiva. O estudo da propagação vegetativa é importante por causa da baixa produção de sementes e existência de diferentes quimiotipos da espécie. O objetivo do presente trabalho foi verificar o efeito de ácido indolbutirico (AIB) na produção de mudas por estacas de C. zehntneri. Os tratamentos foram as concentrações zero, $1.000,2.000,3.000,4.000$ e $5.000 \mathrm{mg} \mathrm{L}^{-1}$ de AIB. O delineamento experimental foi em blocos ao acaso, com seis tratamentos e quatro repetições de 10 estacas por parcela. Foram analisadas aos 40 dias as seguintes características: porcentagem de enraizamento, número e comprimento das raízes por estaca, número de brotações, número de folhas, massa seca foliar e de raízes. A porcentagem de enraizamento foi maior nas maiores concentrações de AIB 3.000, $4.000 e$ $5.000 \mathrm{mg} \mathrm{L}^{-1}$ (80, 90 e 100\%). A porcentagem de enraizamento, o número e comprimento das raízes e o número de folhas apresentaram comportamento linear em relação às concentrações de AIB, quanto maior a concentração maior o valor da característica. $O$ número de brotações diminuiu com a maior concentração de AIB. A massa seca das raízes foi maior nos pré-tratamentos com 4.000 e $5.000 \mathrm{mg} \mathrm{L}^{-1} \mathrm{AIB}$ $(0,35 \mathrm{~g})$. O pré-tratamento das estacas de C. zehntneri com solução de AIB na concentração de $4.000 \mathrm{mg} \mathrm{L}^{-1}$ por 10 segundos é recomendado para a propagação vegetativa.

Palavras-chave: propagação vegetativa, enraizamento, auxina, canelinha, caatinga.

\section{ABSTRACT}

Croton zehntneri Pax et Hoffm. (canela de cunhã) is native to northeastern Brazil, has antioxidant, antinociceptive and antidepressant properties. The study of vegetative propagation is important because of the low seeds production and the existence of different chemotypes in the species. The aim of this study was to assess the effect of indole butyric acid (IBA) in plant propagation by cuttings of C. zehntneri. The experimental design was randomized blocks with six treatments and four replications of 10 cuttings. The treatments were zero concentrations, 1,000, 2,000, 3,000, 4,000 and 5,000 $\mathrm{mg} \mathrm{L}^{-1}$ IBA. It was analyzed the following characteristics: rooting percentage, root number per cutting, root length, shoot number, number of leaves, leaf dry mass and roots dry mass. The rooting percentage was higher for higher concentrations of IBA 3,000, 4,000 and 5,000 mg $L^{-1}$ (80, 90 and 100\%). The percentage of rooting, root number, root length and number of leaves showed linear behavior in relation to concentrations of IBA, the higher the concentration the greater the value of the variable. The number of shoots decreased at higher concentration. The dry mass of roots was higher in pre-treatment with 4,000 and 5,000mg $L^{-1}$ IBA $(0.35 \mathrm{~g})$. Pre-treatment of cuttings of $C$. zehntneri with a solution of IBA at a concentration of $4,000 \mathrm{mg} \mathrm{L}^{-1}$ for 10 seconds is recommended for vegetative propagation of the species.

Key words: vegetative propagation, rooting, auxin, canelinha, caatinga.

\section{INTRODUÇÃO}

Croton zehntneri Pax et Hoffm. (Euphorbiaceae), conhecida popularmente como canela de cunhã, canelinha, canelinha-brava ou canela-brava, é uma planta subarbustiva e caducifólia do Nordeste brasileiro, cujas folhas e hastes são dotadas de aroma

IDepartamento de Ciências Vegetais, Universidade Federal Rural do Semi-Árido (UFERSA), Mossoró, RN, Brasil.

IISetor de Desenvolvimento Rural, Universidade da Integração Internacional da Lusofonia Afro Brasileira, Av. da Abolição, 7, 62790-000, Redenção, CE, Brasil. E-mail: coelhomfstrela@gmail.com.*Autor para correspondência. 
que lembra uma mistura de erva-doce e cravo-da-Índia (LORENZI \& MATOS, 2008). C. zehntneri é usada na medicina popular principalmente como sedativa, como estimulante de apetite e para aliviar distúrbios intestinais (AGRA et al., 2008; LORENZI \& MATOS, 2008), sendo comprovada a atividade antinociceptiva (OLIVEIRA et al., 2001), antioxidante (MORAIS et al., 2006), antifúngica (LIMA et al., 2008) e os efeitos depressivos do óleo essencial de suas folhas sobre o sistema nervoso central em ratos e camundongos (BATATINHA et al., 1991).

A espécie é herbácea anual ou perene e sua multiplicação é feita apenas por sementes (LORENZI \& MATOS, 2008). C. zehntneri, como a maioria das plantas medicinais nativas utilizadas pela população, desenvolvese naturalmente na caatinga no nordeste brasileiro. Acoleta indiscriminada, sem qualquer critério técnico, pode representar risco para o consumidor do fitoterápico, já que pode ocorrer a troca de espécies ou a mistura com outros materiais indesejáveis, além da erosão desse recurso genético e do risco de extinção, pela exploração predatória(CORRÊA JÚNIOR et al., 2004).

Torna-se clara a crescente necessidade do estudo da espécie pela importância de uso pela população local e importância científica. Informações sobre a propagação de $\boldsymbol{C}$. zehntneri não são encontradas na literatura. A produção de sementes de C. zehtneri é baixa, devido ao florescimento ocorrer no período de seca e o aborto de botões florais e flores fecundadas ser alto nesse período, conforme foi observado pelos autores deste trabalho no período de janeiro de 2008 a dezembro de 2009 em Areia BrancaRN. Distinguem-se quatro quimiotipos C. zehntneri, anetol, eugenol, metil-eugenol e estragol (MORAIS et al., 2006), e pode ser importante selecioná-los e mantêlos por propagação vegetativa, desde que as plantas tenham estabilidade genética garantida, o que implicará na formação de plantas uniformes e mais produtivas (HARTMANN et al., 2004).

A propagação por estaquia é considerada uma importante ferramenta no melhoramento de espécies lenhosas e herbáceas, especialmente no cultivo de plantas medicinais (EHLERT et al., 2004). Nesse sentido, algumas espécies medicinais já foram estudadas quanto à estaquia, tais como: Lippia alba (BIASI \& COSTA, 2003), Ocimum gratissimum (EHLERT et al., 2004), Baccharis articulata, Baccharis trimera e Baccharis stenocephala (BONA et al., 2005a e 2005b), Ocimum selloi (COSTA et al., 2007) e Hyptis suaveolens (MAIA et al., 2008).

A aplicação de reguladores vegetais tem sido utilizada com frequência, a fim de proporcionar melhoria do enraizamento, principalmente com uso do ácido indol butírico - AIB (BIASI, 2002). As auxinas são os reguladores vegetais com maior efetividade na promoção do enraizamento (FACHINELLO et al., 2005), entretanto, a concentração hormonal necessária é variável para cada espécie e o tipo de regulador tem resposta diferente devido às raízes serem muito sensíveis a essas substâncias e qualquer acréscimo, além do necessário, pode tornar-se inibitório à formação de raízes adventícias (ALVARENGA \& CARVALHO, 1983).

A baixa produção de sementes aliada à importância da propagação vegetativa para o cultivo de diferentes quimiotipos de $\boldsymbol{C}$. zehtneri motivaram a condução do presente trabalho, que teve o objetivo de verificar o efeito de ácido indolbutírico (AIB) na produção de mudas por estaquia desta espécie.

\section{MATERIAL E MÉTODOS}

O experimento foi desenvolvido em casa de vegetação do Departamento de Ciências Ambientais no Campus da Universidade Federal Rural do SemiÁrido (UFERSA), no município de Mossoró, estado do Rio Grande do Norte, com coordenadas geográficas $5^{\circ} 11^{\prime \prime S}$ e $37^{\circ} 20^{\prime \prime W}$. O período de condução do estudo ocorreu na estação seca, nos meses de setembro a outubro de 2010.

O material propagativo empregado no experimento foi obtido do município de Areia Branca, Rio Grande do Norte, coordenadas $4^{\circ} 57^{\prime}$ S e $37^{\circ} 08^{\prime} \mathrm{W}$. Os ramos de $\boldsymbol{C}$. zehtneri foram coletados em plantas adultas, embalados com jornais umedecidos e armazenados em isopor até chegar à UFERSA, onde foi realizada a implantação imediata do experimento.

As estacas sem folhas foram padronizadas com diâmetro variando de 4,7 a 5,5mm e comprimento de aproximadamente $15 \mathrm{~cm}$, com cortes retos na porção superior e em bisel na base. O ácido indol butírico (AIB) foi utilizado na forma de solução alcoolica em diferentes concentrações, na qual as bases das estacas foram imersas por um período de 10 segundos. O delineamento experimental foi em blocos ao acaso, com seis tratamentos (zero, 1.000, 2.000, 3.000, 4.000 e 5.000mg $\mathrm{L}^{-1}$ de $\left.\mathrm{AIB}\right)$ e quatro repetições de 10 estacas por parcela.

As estacas foram colocadas individualmente em sacolas pretas de polipropileno contendo solo da área de coleta das estacas, mantidas em casa-de-vegetação com irrigação diária. Aos 40 dias, as estacas foram retiradas, sendo analisadas as seguintes características: porcentagem de enraizamento (estacas com raízes); número de raízes (total de raízes emitidas por estaca); comprimento da maior raiz formada por estaca $(\mathrm{cm})$; número de brotações 
(número de brotações por estaca); número de folhas; massa seca foliar e de raízes (mg).

Os dados foram submetidos à análise de variância e feita analise de regressão. As análises foram realizadas pelo programa estatístico SAEG (RIBEIRO JUNIOR \& MELO, 2009).

\section{RESULTADOS E DISCUSSÃO}

A porcentagem de enraizamento teve comportamento linear em relação às concentrações de AIB e foi maior nas maiores concentrações de AIB 3.000 4.000 e $5.000 \mathrm{mg} \mathrm{L}^{-1}$, correspondendo a 80,90 e $100 \%$ de enraizamento, respectivamente (Figura 1A), indicando que a espécie responde bem à aplicação de AIB. Resultados semelhantes foram encontrados por outros autores em diferentes espécies. Em trabalho conduzido por OLIVEIRA et al. (2011), verificou-se que a maior taxa de enraizamento em estacas de Hyptis leucocephala e Hyptis platanifolia foi obtida com 2000 e $4000 \mathrm{mg} \mathrm{L}^{-1}$ deAIB. Aaplicação de 1.000 a $2.000 \mathrm{mg} \mathrm{L}^{-1}$ de AIB proporcionou os melhores índices de enraizamento e sobrevivência de miniestacas em clones de Eucalyptus grandis (TITON et al., 2003). GOULART et al. (2008) verificaram que doses acima de 500 $\mathrm{mg} \mathrm{L}^{-1}$ de AIB foram mais eficientes nos quatro clones de eucalipto estudados. No entanto, a partir de $2000 \mathrm{mg} \mathrm{L}^{-1}$ de AIB, os autores notaram certos níveis de toxicidade em alguns clones. Por outro lado, o aumento das doses de AIB inibiu o enraizamento de estacas de clones de guaranazeiro (ATROCH, 2007), confirmando RAMOS et al. (2003), que afirmaram que o fornecimento exógeno de auxina, em certas quantidades, pode promover uma alteração hormonal, favorecendo ou não o enraizamento de estacas.

O número e o comprimento da maior raiz apresentaram comportamento linear em relação às concentrações de AIB (Figura 1B e 1C). OLIVEIRA et al. (2005) verificaram efeitos positivos no uso de AIB para o aumento do número de raízes nas estacas semilenhosas e lenhosas de pessegueiro (Prunus persica L.), tendo como melhor resultado a cv. 'Simuelo' para a estaca semilenhosa com $1.500 \mathrm{mg} \mathrm{L}^{-1}(41,6)$ e $3.000 \mathrm{mg} \mathrm{L}^{-1}(51,5)$. Segundo os mesmos autores, esses resultados foram associados ao balanço hormonal endógeno, associado à concentração exógena da
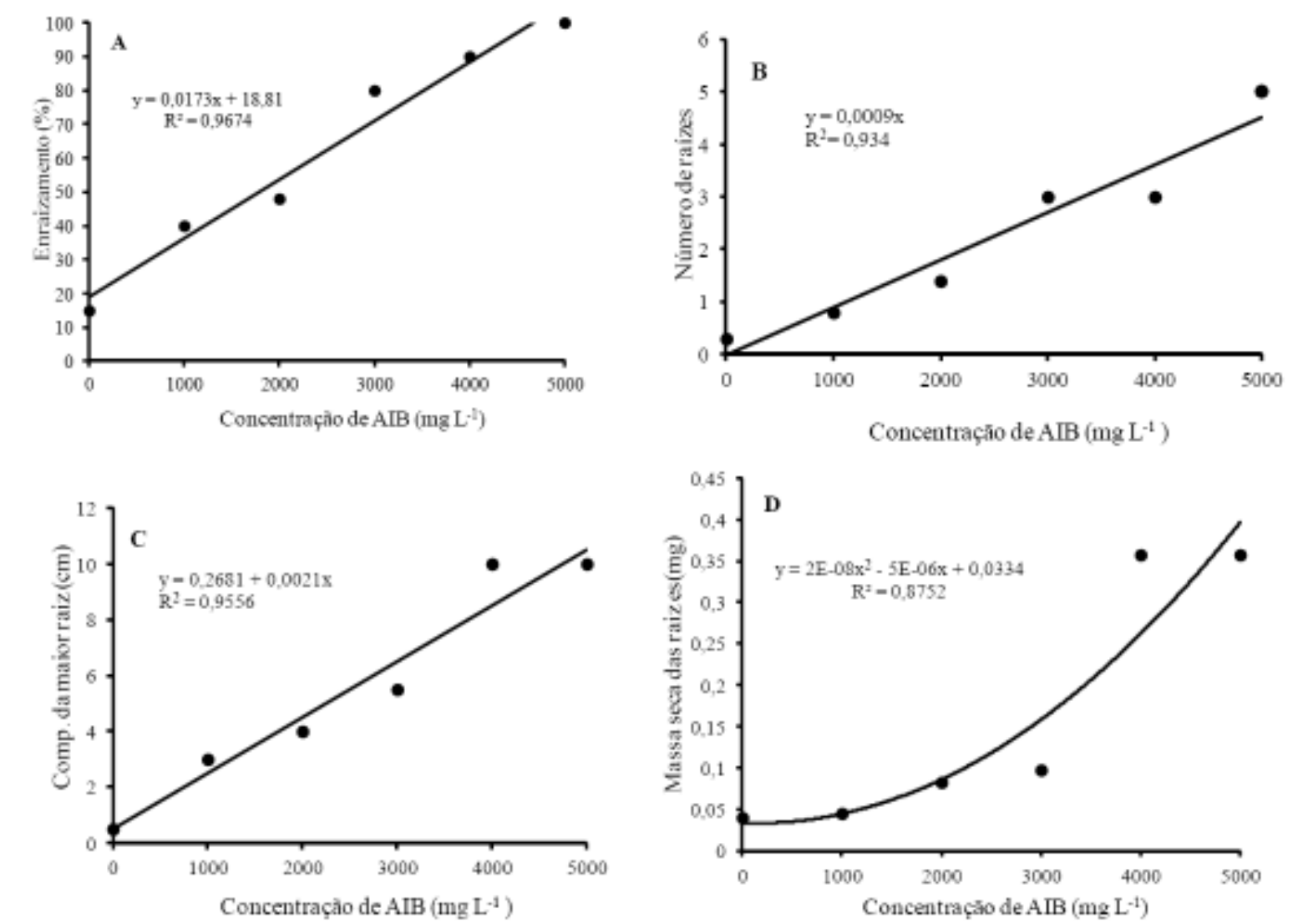

Figura 1 - Porcentagem de enraizamento (A), número de raízes (B), comprimento da maior raiz (C) e massa seca de raízes (D) de estacas de canela de cunhã (Croton zehtneri) em diferentes concentrações de AIB. Mossoró-RN, UFERSA, 2010.

Ciência Rural, v.42, n.4, abr, 2012. 
auxina AIB com o potencial genético de cada variedade estudada.

SCALOPPI JUNIOR (2007) observou em diferentes espécies de Annonaceae que Rollinia silvatica apresentou nas estacas apenas nove raízes, com comprimento de $3 \mathrm{~cm}$ nos tratamentos com 100 e 200 $\mathrm{mg} \mathrm{L}^{-1}$ de AIB, já, para Rollinia emarginata, os resultados foram inferiores, sendo que somente o tratamento com 400 $\mathrm{mg} \mathrm{L}^{-1}$ de AIB apresentou uma raiz com $1 \mathrm{~cm}$ de comprimento, demonstrando a influência do potencial genético nas espécies de Annonaceae. GONTIJO et al. (2003), trabalhando com estacas de acerola (Malpighia glabra L.), com dois pares de folhas e diferentes concentrações de AIB $(0 ; 1.600$; 2.000; 2.400 e $2.800 \mathrm{mg} \mathrm{L}^{-1}$ ), verificaram que o maior comprimento de raiz $(9 \mathrm{~cm})$ foi obtido na maior concentração de AIB, concordando com os resultados obtidos no presente trabalho, ou seja,10 cm na concentração $4.000 \mathrm{mg} \mathrm{L}^{-1} \mathrm{AIB}$.

A massa seca das raízes teve comportamento quadrático e foi maior nos pré- tratamentos com 4.000 e $5.000 \mathrm{mg} \mathrm{L}^{-1}$ de AIB, (0,35 g). GONTIJO et al. (2003) obtiveram melhores resultados em aceroleira (Malpighia glabra L.) com menor concentração de AIB (2.800 $\left.\mathrm{mg} \mathrm{L}^{-1}\right)$, o que proporcionou maior número e massa seca das raízes, enquanto PIO et al. (2003) obtiveram maior massa seca de raízes de figueira (Ficus carica L.) em estacas tratadas com 4000 $\mathrm{mg} \mathrm{L}^{-1}$. HARTMANN et al. (2004) afirmaram que a maior ou menor capacidade das estacas enraizarem depende do balanço entre as substâncias promotoras e inibidoras de enraizamento, que, de modo geral, é muito variável entre as espécies.

O número de folhas apresentou comportamento linear em relação às concentrações de AIB (Figura 2A) e o número de brotações e massa seca foliar, comportamento quadrático (Figura 2B e 2C). O número de brotações foi significativamente superior nas concentrações de 2000, 3000 e 4000 $\mathrm{mg} \mathrm{L}^{-1}$ de AIB, enquanto que a testemunha e as concentrações 1.000 e $5.000 \mathrm{mg} \mathrm{L}^{-1}$ apresentaram o mesmo resultado, demonstrando que concentrações mais elevadas de

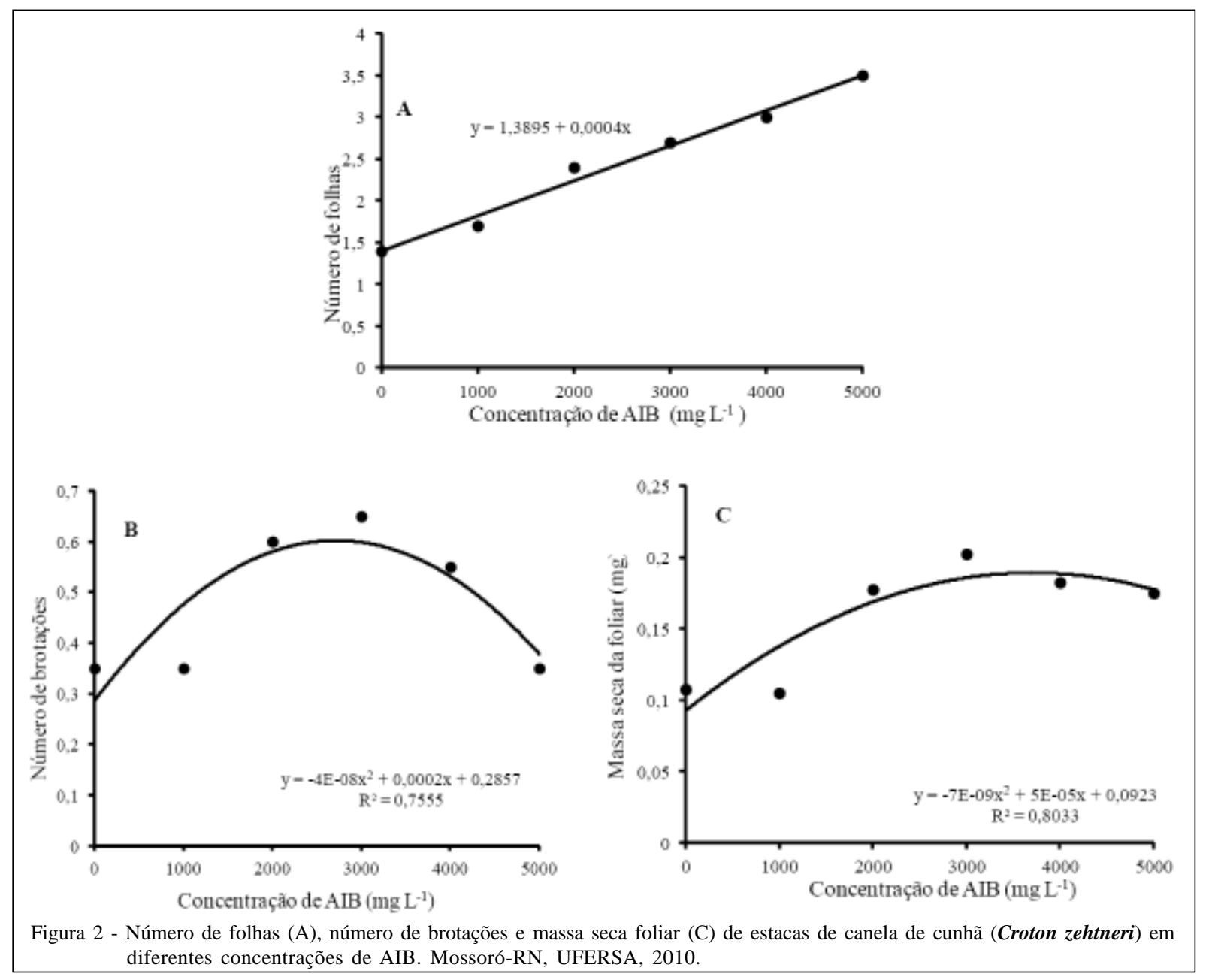

Ciência Rural, v.42, n.4, abr, 2012. 
AIB podem ter efeito inibitório na produção de brotações nas estacas da espécie. Possivelmente, nesses tratamentos, houve desbalanceamento entre auxinas, giberelinas e citocininas, desfavorecendo o crescimento dos brotos. DELGADO \& YUYAMA (2010) observaram efeito negativo do AIB no número de brotações de estacas de camu-camu e OLIVEIRA et al. (2008) também verificaram que maiores concentrações de AIB diminuíram o número de brotações em Lippia sidoides Cham.

C. zehntneri é uma espécie nativa herbácea que responde ao uso de AIB, o que é bem positivo para salvaguardá-la e colocá-la em cultivo comercial. Maiores doses de AIB aumentam o enraizamento de $\boldsymbol{C}$. zehntneri e também o número de folhas e de raízes, proporcionando raízes mais longas e com maior massa. Considerando o número de folhas, a porcentagem de enraizamento, o comprimento da maior raiz e a massa seca de raízes, verifica-se que as maiores concentrações de AIB (4.000 e 5.000 $\mathrm{mg} \mathrm{L}^{-1}$ ) podem ser usadas com eficiência no enraizamento de estacas de $\boldsymbol{C}$. zehtneri. Como os resultados são os mesmos, é preferível usar $4.000 \mathrm{mg} \mathrm{L}^{-1}$ de AIB para reduzir os custos, desde que o preço do regulador seja elevado.

\section{CONCLUSÃO}

O pré-tratamento das estacas de $\boldsymbol{C}$. zehntneri com solução de AIB na concentração de $4.000 \mathrm{mg} \mathrm{L}^{-1}$ por 10 segundos é recomendado para a propagação vegetativa da espécie.

\section{AGRADECIMENTOS}

Ao Conselho Nacional de Desenvolvimento Científico e Tecnológico (CNPq), pela Bolsa de Produtividade em Pesquisa concedida a terceira autora.

\section{REFERÊNCIAS}

AGRA, M.F. et al. Survey of medicinal plants used in the region Northeast of Brazil. Revista Brasileira de Farmacognosia, v.18, p.472-508, 2008. Disponível em: <http://www.scielo.br/ pdf/rbfar/v18n3/a23v18n3.pdf>. Acesso em: 13 maio, 2011.

ALVARENGA, L.R.; CARVALHO, V.D. Uso de substâncias promotoras de enraizamento de estacas de frutíferas. Informe Agropecuário, v.9, p.47-55, 1983.

ATROCH, A.L. et al. Enraizamento de estacas de clones de guaranazeiro tratados com ácido indol-3-butírico (AIB) Revista de Ciências Agrárias, v.47, p.103-111, 2007. Disponível em: <http://www.ajaes.ufra.edu.br/ajaes/index.php/ ajaes/article/viewFile/198/88>. Acesso em: 13 maio, 2011.

BATATINHA, M.J.M. et al. Croton zehntneri: possible central nervous system effects of the essential oil in rodents. Journal of Ethnopharmacology, v.33, n.3, p.285-287, 1991.
Disponível em: <http://www.ncbi.nlm.nih.gov/pubmed/ 7739227>. Acesso em: 13 maio, 2011.

BIASI, L.A. Reguladores de crescimento vegetal. In: WACHOWICZ, C.M.; CARVALHO. R.I.N. Fisiologia vegetal: produção e pós-colheita. Curitiba: Champagnat, 2002. 424p.

BIASI, L.A.; COSTA, G. Propagação vegetativa de Lippia alba. Ciência Rural, v.33, p.455-459, 2003. Disponível em:<http://www.scielo.br/pdf/cr/v33n3/a10v33n3.pdf >. Acesso em: 13 jun. 2011.

BONA, C.M. et al. Estaquia de três espécies de Baccharis Ciência Rural, v.35, p.223-226, 2005a. Disponível em: <http://www.scielo.br/pdf/cr/v35n1/a37v35n1.pdf>. Acesso em: 13 mar. 2011.

BONA, C.M. et al. Propagação por estaquia de Baccharis articulata (Lam.) Pers., Baccharis trimera (Less.) A.P. de Candolle e Baccharis stenocephala Baker com uso de auxinas. Revista Brasileira de Plantas Medicinais, v.7, p.26-31. 2005b. Disponível em: <http://www.ibb.unesp.br/servicos/ publicacoes/rbpm/pdf_v7_n2_2005/artigo_6_v7_n2.pdf >. Acesso em: 10 jun. 2011

CORRÊA JÚNIOR, C. et al. Complexo agroindustrial das plantas medicinais, aromáticas e condimentares no Estado do Paraná. Curitiba: Sociedade Paranaense de Plantas Medicinais; EMATER-PR: Embrapa florestas, 2004. 272p. Disponível em: <http://livraria.sct.embrapa.br/liv_resumos/pdf/ 00077240.pdf>. Acesso em: 03 out. 2011.

COSTA, L.C.B. et al. Comprimento da estaca e tipo de substrato na propagação vegetativa de atroveran. Ciência Rural, v.37, p.1157-1160, 2007. Disponível em: <http://www.scielo.br/pdf/ cr/v37n4/a40v37n4.pdf>. Acesso em: 13 jun. 2011.

DELGADO, J.P.M.; YUYAMA, K. Comprimento de estaca de camu-camu com ácido indolbutírico para a formação de mudas. Revista Brasileira de Fruticultura, v.32, p.522-526, 2010. Disponível em: <http://www.scielo.br/pdf/rbf/v32n2/ aop07010.pdf>. Acesso em: 11 jun. 2011.

EHLERT, P.A.D. et al. Propagação vegetativa da alfavacacravo utilizando diferentes tipos de estacas e substratos. Horticultura Brasileira, v.22, p.10-13, 2004. Disponível em: <http://www.scielo.br/pdf/hb/v22n1/a02v22n1.pdf $>$. Acesso em: 10 jun. 2011.

FACHINELLO, J.C. et al. Propagação de plantas frutíferas. Brasília: Embrapa Informação Tecnológica, 2005. p.155-173.

GONTIJO, T.C.A. et al. Enraizamento de diferentes tipos de estacas de aceroleira utilizando ácido indolbutírico. Revista Brasileira de Fruticultura, v.25, p.290-292, 2003. Disponível em: <http://www.scielo.br/pdf/rbf/v25n2/ a27v25n2.pdf>. Acesso em: 10 jun. 2011.

GOULART, P.B. et al. Efeito dos reguladores de crescimento AIB e ANA no enraizamento de miniestacas de clones de Eucalyptus grandis X Eucalyptus urophylla. Revista Árvore, v.29, p.1051-1058, 2008. Disponível em: <http://www.scielo.br/ pdf/rarv/v32n6/a10v32n6.pdf $>$. Acesso em: 13 jun. 2011.

HARTMANN, H.T. et al. Plant propagation: principles and practices. 8.ed. New Jersey: Prentice Hall, 2004. 880p. 
LIMA, F.C. et al. Croton zehntneri essential oil prevents acetaminopheninduced acute hepatotoxicity in mice. Records of Natural Products, v.2, p.135-140, 2008. Disponível em: <http://www.acgpubs.org/RNP/2008/Volume\%202/Issue\%201/ 5-RNP0808-39press.pdf $>$. Acesso em: 13 jun. 2011.

LORENZI, H.; MATOS, F.J.A. Plantas medicinais do Brasil: nativas e exóticas. 2.ed. Nova Odessa, SP: Instituto Plantarum, 2008. 544p.

MAIA, S.S.S. et al. Enraizamento de Hyptis suaveolens (L.) Poit. (Lamiaceae) em função da posição da estaca no ramo. Revista Brasileira de Ciências Agrárias, v.3, p.317-320, 2008. Disponível em: <http://www.agraria.pro.br/sistema/ index.php?journal=agraria \&page =article \&op= view\&path\%5B\%5D=330\&path\%5B\%5D=222>. Acesso em: 5 jun. 2011.

MORAIS, S.M. et al. Atividade antioxidante de óleos essenciais de espécies de croton do nordeste do Brasil. Química Nova, v.29, p.907-910, 2006.

OLIVEIRA, A.C. et al. Antinociceptive effects of the essential oil of Croton zehntneri in mice. Brazilian Journal of Medical and Biological Research, v.34, p.1471-1474, 2001. Disponível em: <http://scielo.isciii.es/pdf/bjmbr/v34n11/ 3888.pdf>. Acesso em: 5 jun. 2011.

OLIVEIRA, A.P. et al. Qualidade do sistema radicular de estacas semilenhosas e lenhosas de pessegueiro tratadas com AIB. Revista Brasileira Fruticultura, v.27, p.346-348, 2005. Disponível em: <http://www.scielo.br/pdf/rbf/v27n2/ a42v27n2.pdf>. Acesso em: 13 jun. 2011.

OLIVEIRA, G.L. et al. Enraizamento de estacas de Lippia sidoides Cham. utilizando diferentes tipos de estacas, substratos e concentrações do ácido indolbutírico. Revista Brasileira de Plantas Medicinais, v.10, p.12-17, 2008. Disponível em: <http://www.ibb.unesp.br/servicos/publicacoes/rbpm/ pdf_v10_n4_2008/artigo3_p12-17.pdf>. Acesso em: 13 jun. 2011.

OLIVEIRA, L.M. et al. Propagação vegetativa de Hyptis leucocephala Mart. ex Benth. e Hyptis platanifolia Mart. ex Benth. (Lamiaceae). Revista Brasileira de Plantas Medicinais, v.13, p.73-78, 2011. Disponível em: <http:// www.scielo.br/pdf/rbpm/v13n1/v13n1a11.pdf>. Acesso em: 11 jun. 2011.

PIO, R. et al. Enraizamento de estacas apicais de figueira tratadas com sacarose e ácido indolbutírico por imersão rápida. Revista Brasileira de Agrociência, v.9, n.1, p.35-38, 2003. Disponível em: <http://www.ufpel.tche.br/faem/agrociencia/ v9n1/artigo06.pdf>. Acesso em: 03 out. 2011.

RAMOS, J.D. et al. Enraizamento de estacas herbáceas de 'Mirabolano' (Prunus cerasifera Ehrn) em diferentes substratos e concentrações de ácido indolbutírico. Revista Brasileira de Fruticultura, v.25, p.189-191. 2003. Disponível em: <http://www.scielo.br/pdf/rbf/v25n1/a53v25n1.pdf>. Acesso em: 11 jun. 2011.

RIBEIRO JUNIOR, J.I.; MELO, A.L.P. Guia prático para utilização do SAEG. Viçosa: Editora Independente, 2009. 287p.

SCALOPPI JUNIOR, E.J. Propagação de espécies de Annonaceae com estacas caulinares. 2007. 87f. Tese (Doutorado em Produção Vegetal) - Universidade Estadual Paulista Julio de Mesquita Filho. Jaboticabal, SP.

TITON, M. et al. Efeito do AIB no enraizamento de miniestacas e microestacas de clones de Eucalyptus grandis W. Hill ex Maiden. Revista Árvore, v.27, p.1-7, 2003. Disponível em: $<$ http://www.scielo.br/pdf/rarv/v27n1/15915.pdf>. Acesso em: 10 jun. 2011. 